\title{
THREE PORT VERSUS FOUR PORT CHOLECYSTECTOMY- A RETROSPECTIVE DESCRIPTIVE STUDY
}

\author{
Mahesh Chandra Pandey'1, S. P. Mishra², H. S. Nagar ${ }^{3}$, H. S. Rawat ${ }^{4}$, R. K. Shrivastava ${ }^{5}$ \\ 1 Assistant Professor, Department of General Surgery, TSM Medical College and Hospital, Lucknow, Uttar Pradesh. \\ ${ }^{2}$ Assistant Professor, Department of General Surgery, TSM Medical College and Hospital, Lucknow, Uttar Pradesh. \\ 3 Professor, Department of General Surgery, TSM Medical College and Hospital, Lucknow, Uttar Pradesh. \\ 4 Professor and HOD, Department of General Surgery, TSM Medical College and Hospital, Lucknow, Uttar Pradesh. \\ 5 Professor, Department of General Surgery, TSM Medical College and Hospital, Lucknow, Uttar Pradesh.
}

\section{BACKGROUND} ABSTRACT

Various modifications have been tried in laparoscopic cholecystectomy since its introduction. One, two and three port LC have been performed on limited scale. Our aim was to compare three port LC with four port LC in patients with cholelithiasis. The main objective of this study was to evaluate the outcome of 3 port LC for treatment of cholelithiasis by comparing the result with 4 port LC with respect to safety and efficacy.

\section{MATERIALS AND METHODS}

In this comparative study, a total of 150 patients of laparoscopic cholecystectomy for gall stone disease were studied by dividing them into two groups. The results were compared in terms of complications, conversion from 3 port to 4 port and from LC to open procedure, hospital stay, pain score, operative time, need of analgesia and bile duct injury.

\section{RESULTS}

A total of 150 patients of cholelithiasis were treated by laparoscopic cholecystectomy. Three port LC was performed in 60 (40\%) patients and 4 port LC was performed in 90 (60\%) patients. In group 1, 44.4\% patients complained of mild pain and 55.5\% experienced moderate-to-severe pain on VAS post-operatively, while in group $270 \%$ patients complained of mild pain and $30 \%$ patients complained of moderate-to-severe pain post-operatively. There was no bile duct injury reported in either group. However, in group 2 (3 port LC) 3 cases (5\%) converted to 4 port LC and there was no conversion (open) reported in group 1 (4 port LC).

\section{CONCLUSION}

In this comparative study, we found that use of 3 port LC did not affect the procedure safety, conversion rate, operating time and complication rate. Three port LC is routine in our institute and used by experienced surgeons, needed fewer painkillers, shorter hospital stay and more cost effective.

\section{KEYWORDS}

Cholelithiasis, 3 Port Laparoscopic Cholecystectomy.

HOW TO CITE THIS ARTICLE: Pandey MC, Mishra SP, Nagar HS, et al. Three port versus four port cholecystectomy- a retrospective descriptive study. J. Evolution Med. Dent. Sci. 2018;7(10):1178-1181, DOI: 10.14260/jemds/2018/269

\section{BACKGROUND}

Gall stone are one of the major causes of morbidity and mortality all over the world. The common presentation of cholelithiasis is acute cholecystitis, biliary colic, obstructive jaundice and acute pancreatitis. First cholecystectomy was performed in 1882 by Karl Langenbuch. ${ }^{1}$

Various studies had shown that most of the gall bladder stone were asymptomatic and cholecystectomy was the gold standard surgical treatment of cholelithiasis. In the current laparoscopic era surgical treatment of cholelithiasis has changed, now laparoscopic cholecystectomy is the gold standard surgical treatment of cholelithiasis.

The laparoscopic procedure was found to cause less scarring, shorter hospital stay and faster recovery than open procedure, but probably at the expense of a higher rate of

'Financial or Other Competing Interest': None.

Submission 23-01-2018, Peer Review 17-02-2018,

Acceptance 22-02-2018, Published 05-03-2018.

Corresponding Author:

Mahesh Chandra Pandey,

536/53 KMA, Durga Mandir,

Madeh Gani, Sitapur Road,

Lucknow-226020, Uttar Pradesh.

E-mail: mp211177@gmail.com

DOI: $10.14260 /$ jemds $/ 2018 / 269$ bile duct injuries. ${ }^{2}$ Post-operative pain and cosmesis and later complication like incisional hernia and intestinal obstruction should help to decide which technique is better. ${ }^{3}$

Laparoscopic cholecystectomy is one of the most commonly performed operations in general surgery and considered standard care for symptomatic gall stone. ${ }^{4}$ Laparoscopic cholecystectomy was first performed in 1987 by Philip Mouret. Laparoscopic cholecystectomy traditionally performed through four port, 5 but recently to reduce analgesia need and obtain a better cosmetic result one, two and three port LC has been performed.6,7 Although, three port cholecystectomy is not common, research has demonstrated that it is a safe and feasible surgical technique. 7,8

\section{MATERIALS AND METHODS}

This comparative study was carried out in the Department of General Surgery of TSM Medical College and Hospital, Lucknow. Objective of this study was to compare the safety and effectiveness of three port LC with four port LC. Records of the total 150 patients of cholelithiasis who underwent laparoscopic cholecystectomy were taken from the MRD, out of which 90 patients were treated with 4 port LC and 60 were treated with 3 port LC.

Patients with $\mathrm{H} / \mathrm{O}$ acute pain in abdomen within 1 month of period, finding of the gall bladder wall thickening in USG, 
suspected CBD stones, $\mathrm{H} / \mathrm{O}$ obstructive jaundice, gall stone pancreatitis, acute cholangitis and ERCP in less than 10 days were excluded from the surgery.

\section{Design}

Retrospective Descriptive study.

\section{Study Period}

2 years.

\section{Study Population}

In this comparative study, minimum age of the patient was 17 years and maximum was 65 years. Out of 150 cholelithiasis patients, there were 10 males and 80 females and 103 patients were from rural area and 47 were from urban area. Three port LC is routinely performed by experienced surgeons in General Surgery Department of our institute. During three port LC, both $10 \mathrm{~mm}$ port were similar as in four port LC. While third port was placed at right mid-clavicular line just below the costal margin, position of the patient, surgeon, cameraman and screen were same as in four port LC. A grasper was introduced from $5 \mathrm{~mm}$ port to hold the infundibulum of the gall bladder for retraction of the liver. After careful visualisation of the Calot's triangle, dissection of the cystic artery and duct were done, and both were cut after clipping. Gall bladder was removed from epigastric port and a drain was placed from $5 \mathrm{~mm}$ port when necessary (Picture 1).

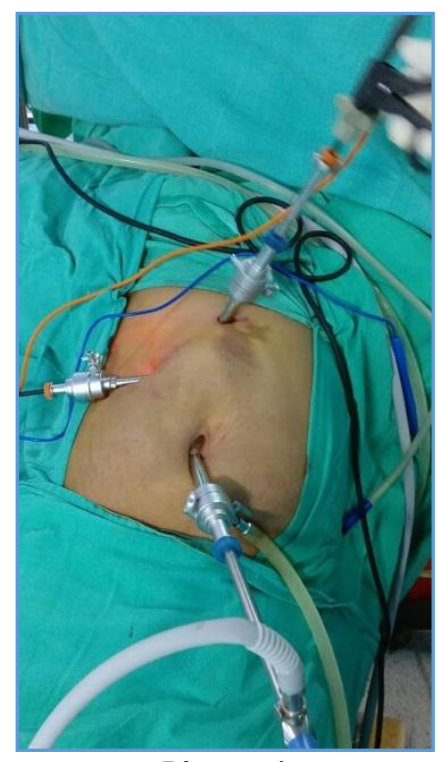

Picture 1

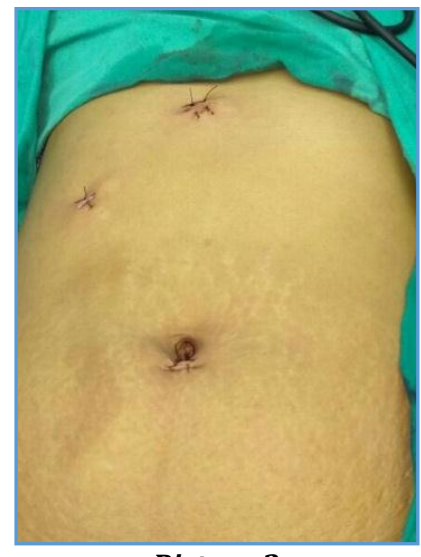

Picture 2
In both Groups, Observations have been made for Comparing with the following Format-

- Age, sex and geographical distribution.

- Time taken for surgery.

- Complications.

- Conversion (3 port to 4 port and 4 port to open LC).

- Pain score.

- Duration of hospital stay.

In this study, IBM-compatible statistical package version 20.0 was used. Continuous quantitative data were expressed as mean \pm standard deviation (SD). In this study, $p$ value at $<0.5$ was considered significant and at $>0.5$ was considered not significant, while $<0.001$ was considered highly sensitive.

\section{RESULTS}

In this study, we divided 150 patients of laparoscopic cholecystectomy into 2 groups. Group 1 of four port LC (90) and Group 2 of three port LC (60). Pre-operative diagnosis in all the patients of both groups was similar.

In group I $88.88 \%$ of the 90 patients were female and $11.11 \%$ were male. While in group II, $90 \%$ of the 60 patients were female and $10 \%$ were male.

\begin{tabular}{|c|c|c|c|c|}
\hline \multicolumn{5}{|c|}{ Sex Ratio } \\
\hline Sex & Group I & $\mathbf{\%}$ & Group II & $\mathbf{\%}$ \\
\hline Female & 80 & $88.8 \%$ & 54 & $90 \%$ \\
\hline Male & 10 & $11.11 \%$ & 6 & $10 \%$ \\
\hline Total & $\mathbf{9 0}$ & & $\mathbf{6 0}$ & \\
\hline \multicolumn{6}{|c|}{ Figure 1. Sex Ratio } \\
\hline
\end{tabular}

In group I 64\% patients came from rural area and 35.5\% from urban area, while in group II $75 \%$ patients came from rural area and $25 \%$ from urban area.

\begin{tabular}{|c|c|c|c|c|}
\hline \multicolumn{5}{|c|}{ Rural (Urban Ratio) } \\
\hline Group & Rural & $\mathbf{\%}$ & Urban & $\mathbf{\%}$ \\
\hline I (90) & 58 & 64 & 32 & 75 \\
\hline II (60) & 45 & 35 & 15 & 25 \\
\hline Total & $\mathbf{1 0 3}$ & & $\mathbf{4 7}$ & \\
\hline \multicolumn{6}{|c}{ Figure 2. Rural/ Urban Ratio } \\
\hline
\end{tabular}

In this study, minimum age of the patient was 16 years and maximum age was 66 years.

\begin{tabular}{|c|c|c|c|c|}
\hline \multicolumn{5}{|c|}{ Age } \\
\hline Age & Group I & $\mathbf{\%}$ & Group II & \% \\
\hline 15 - 35 years & 12 & 13.33 & 14 & 23.3 \\
\hline 36 - 45 years & 48 & 53.33 & 22 & 36.6 \\
\hline $46-60$ years & 22 & 24.44 & 18 & 30 \\
\hline 60 - 70 years & 8 & 8.8 & 6 & 10 \\
\hline Total & $\mathbf{9 0}$ & & $\mathbf{6 0}$ & \\
\hline \multicolumn{6}{|c|}{ Figure 3. Age Distribution } \\
\hline
\end{tabular}

In group I maximum patients came from 36 - 45 years' age group (53.33\%), while in group 2 maximum patients were found in the same age group (36.66\%).

There was no significant difference in operating time between two groups. In Group $156.66 \%$ patients were operated between $1 / 2$ hour and 1-hour time, while in group II $60 \%$ patients were operated in the same time period. $21.11 \%$ patients in group I and $21.66 \%$ patients in group II took more than one hour to complete the procedure. 


\begin{tabular}{|c|c|c|c|c|}
\hline \multicolumn{5}{|c|}{ Time Taken Operation Time } \\
\hline Time & Group I & \% & Group II & $\mathbf{\%}$ \\
\hline <1/2 Hr. & 20 & 22.2 & 11 & 18.3 \\
\hline $1 / 2$ Hr. to 1 Hr. & 51 & 56.6 & 36 & 60 \\
\hline$>1$ Hr. & 19 & 21.1 & 13 & 21.6 \\
\hline Total & $\mathbf{9 0}$ & & $\mathbf{6 0}$ & \\
\hline \multicolumn{5}{|c|}{ P $=0.491$} \\
\hline \multicolumn{6}{|c|}{} \\
\hline
\end{tabular}

In group I 75.5\% patients were discharged within 24 - 48 hrs. and in group II $65 \%$ patients were discharged from the hospital within same time period. $24.4 \%$ patients in group I and $35 \%$ in group II were discharged within 48 - $72 \mathrm{hrs}$. All the patients were admitted in the ward in the evening before surgery.

Intraoperative complications in this study were similar and there was no significant difference in respect to bleeding, wound infection, perforation of gall bladder and spillage of stones.

There was no bile duct injuries reported in either group.

\begin{tabular}{|c|c|c|c|c|}
\hline \multicolumn{5}{|c|}{ Complication } \\
\hline & Group I & $\mathbf{\%}$ & Group II & $\mathbf{\%}$ \\
\hline Bleeding & 12 & 13.3 & 8 & 13.3 \\
\hline Wound Infection & 4 & 4.44 & 3 & 5 \\
\hline Conversion & 3 & 3.33 & 0 & 0 \\
\hline Preparation of GB & 12 & 13.3 & 8 & 13 \\
\hline Spillage of Stone & 11 & 12.2 & 9 & 15 \\
\hline BDI & 0 & - & 0 & - \\
\hline P $=0.456$ \\
\hline \multicolumn{6}{|c|}{ Complications } \\
\hline
\end{tabular}

In group III 3 patients were converted to four port LC, 1 due to bleeding from the cystic artery and two due to dense adhesion around cystic pedicle. There was no conversion reported in group one (four port LC to open).

\begin{tabular}{|c|c|}
\hline \multicolumn{2}{|c|}{ Reason to Convert 3 Port LC to 4 Port LC } \\
\hline & Group II \\
\hline Bleeding & 1 \\
\hline Adhesion & 2 \\
\hline Difficult Calot's triangle & 0 \\
\hline Thick wall gall bladder & 0 \\
\hline \multicolumn{2}{|c|}{ Figure 6. Conversion } \\
\hline
\end{tabular}

Visual analogue scale was used to measure the pain in both groups.

\begin{tabular}{|c|c|c|c|c|c|}
\hline \multicolumn{7}{|c|}{ Verbal Pain Score during 1st 48 Hours } \\
$\begin{array}{c}\text { VAS Grade 1-2 } \\
\text { Mild Pain }\end{array}$ & $\mathbf{\%}$ & $\begin{array}{c}\text { VAS Grade 3-4 } \\
\text { Moderate-to- } \\
\text { Severe }\end{array}$ & $\mathbf{\%}$ & Total \\
\hline Group I & 40 & 44.4 & 50 & 63.5 & 90 \\
\hline Group II & 42 & 70 & 18 & 30 & 60 \\
\hline Total & 82 & & $\mathbf{6 8}$ & & $\mathbf{1 5 0}$ \\
\hline \multicolumn{6}{|c|}{ P= 0.704 } \\
\hline \multicolumn{6}{|c|}{ Figure 7. VAS Score } \\
\hline
\end{tabular}

In group I 40 (44.4\%) patients complained of mild pain (grade 1-2) and 50 (55.5\%) patients complained of moderate-to-severe pain (grade 3 - 4) post-operatively. While in group II, 42 (70\%) patients complained of mild pain and 18
(30\%) patients complained of moderate-to-severe pain postoperatively.

\begin{tabular}{|c|c|c|c|c|}
\hline \multicolumn{5}{|c|}{ Hospital Stay } \\
\hline Duration & Group I & $\mathbf{\%}$ & Group II & \% \\
\hline $24-48$ hrs. & 66 & 73.3 & 40 & 66,6 \\
\hline $48-72$ hrs. & 20 & 22.2 & 20 & 33.33 \\
\hline$>72$ hrs. & 4 & 4.44 & 0 & - \\
\hline Total & 90 & & $\mathbf{6 0}$ & \\
\hline \multicolumn{6}{|c|}{ P $=0.671$} \\
\hline \multicolumn{6}{|c|}{ Figure 8. Hospital Stay } \\
\hline
\end{tabular}

\section{DISCUSSION}

Laparoscopic cholecystectomy is the standard treatment for symptomatic cholelithiasis and is the most commonly performed laparoscopic surgery. Laparoscopic surgery has advantage over open cholecystectomy, as it has better cosmetic results and cost effectiveness. It also has fewer complications and shorter hospital stay.

Now majority of the laparoscopic cholecystectomy cases are performed as day surgery and helps the patients in early recovery and return to work.

Four port LC is the most commonly performed surgery for cholelithiasis, but in recent years various studies of three port, two port and even one port LC (SILS) have been done. The only reported advantage of single incision laparoscopic surgery (SILS) over standard laparoscopic cholecystectomy is an improved cosmetic result. ${ }^{7}$ With gradual and long experience in laparoscopy surgery, now three port LC is routinely performed by experienced surgeon. Multiple study reports that three port LC is safe when performed by experienced surgeons.

In the present study, intra-operative adverse events were similar in both groups and there was no significant difference seen with respect to bleeding, stone spillage and gall bladder perforation.

In meta-analysis of five studies comparing three port and four port LC, the operative time needed for analgesics, success rates and duration of hospital stay were similar. ${ }^{9}$ Research indicates three port LC is safe with some rate of choledochal injury as four port LC.10,8,11 Studies have also shown that the three port technique does not change the rate of conversion or increase the operating time when compared to fourth port technique. 12

In case of dense adhesion or difficulty to identify the structure of Calot's triangle, one should be very careful to identify the cystic artery and duct to avoid the common bile duct injury and surgeon should not hesitate to convert the procedure.

\section{CONCLUSION}

In our institution, 3 port LC is routinely performed by experienced surgeon. Every laparoscopic cholecystectomy is initially performed with 3 port, and 4 th port is used when situation demands.

3 port LC is safe and effective treatment for cholelithiasis as conventional 4 port LC. It also improves cosmesis, save procedure time and needed fewer pain killers, shorter hospital stays and more cost effective when performed by experienced surgeon. 


\section{REFERENCES}

[1] Beal JM. Historical perspective of gallstone disease. Surg Gynecol Obstet 1984;158(2):181-9.

[2] Harboe KM, Bardram L. Nationwide quality improvement of cholecystectomy: results from a national database. Int $\mathrm{J}$ Qual Health Care 2011;23(5):565-73.

[3] Solanki K Parmar H, Gohil V, et al. Comparative study between open $\mathrm{v} / \mathrm{s}$ Lapaoscopic cholecystectomy NJIRM 2010;1(1):18-20.

[4] Macfadyen BV, Vecchio R, Ricardo A, et al. Bile duct injury after laparoscopic chilecystecyomy. The United States experience. Surgical Endoscopy 1998;12(4):315-21.

[5] Olsen DO. Laparoscopic cholecystectomy. Am J surg 2004;161:339-44.

[6] Osborne D, Boe B, Rosemurgy AS, et al. Twentymillimetre laparoscopic cholecystectomy: fewer ports results in less pain, shorter hospitalization and faster recovery. Am Surg 2005;71(4):298-302.
[7] Poon CM, Chan KW, Lee DW, et al. Two-port versus four-port laparoscopic cholecystectomy. Surg Endosc 2003;17(10):1624-7.

[8] Tagaya N, Kita J, Takagi K, et al. Experience with threeport laparoscopic cholecystectomy. J Hepatobiliary Pancreat Surg 1998;5(3):309-11.

[9] Sun S. Three-port vs. standard four port laparoscopic cholecystectomy. Surg Endosc 2003;17:1434-6.

[10] Cerci C, Tarhan OR, Barut I, et al. Three-port versus four-port laparoscopic cholecystectomy. Hepatogastroenterology 2007;54(73):15-6.

[11] Trichak S. Three-port vs. standard four-port laproscopic cholecystectomy. Surg Endosc 2003;17(9):1434-6.

[12] Al-Azawi D, Houssein N, Rayis AB, et al. Three-port versus for port laparoscopic cholecystectomy in acute and chronic cholecystitis. BMC Surgery 2007;7:8. 